\title{
Indigenous Bubble CPAP and Swine Flu Pandemic
}

\author{
Beuy Joob • Viroj Wiwanitkit
}

Received: 10 October 2011 /Accepted: 12 December 2011 /Published online: 23 December 2011

(C) Dr. K C Chaudhuri Foundation 2011

Sir,

The publication on indigenous bubble CPAP and Swine flu pandemic is very informative [1]. Kinikar et al. concluded that "Indigenous NB-CPAP improves hypoxemia and signs and symptoms in hemodynamically stable children with acute respiratory failure due to influenza like illness [1]". Several concerns on this work are to be criticized. The small number of subjects without control group might be a major problem of this work. In addition, the conclusion on the cost effectiveness of the bubble CPAP could not be done without any medical economics analysis. Furthermore, an important concern in using of bubble CPAP is the possibility for inducing nosocomial infection outbreak in cases where no good infection control is implemented [2].

\section{References}

1. Kinikar A, Kulkarni R, Valvi C, Gupte N. Use of indigenous bubble CPAP during swine flu pandemic in Pune, India. Indian J Pediatr. 2011;78:1216-20.

2. Teo WY, Rajadurai VS, Sriram B. Morbidity of parainfluenza 3 outbreak in preterm infants in a neonatal unit. Ann Acad Med Singapore. 2010;39:837-42.

\section{B. Joob $(\bowtie)$}

Sanitation 1 Medical Academic Center,

Bangkok, Thailand

e-mail: beuyjoob@hotmail.com

V. Wiwanitkit

Wiwanitkit House,

Bangkhae,

Bangkok, Thailand

\section{Authors' Reply}

Sir,

We thank Dr Joob and Dr Wiwanitkit for their valuable comments on our work.

This study was carried out at the height of the Swine flu Pandemic situation in Pune,India. The indigenous nasal Bubble CPAP was invented because it was the need of time and our initial results show that it is effective. This effectiveness under pandemic situation was the reason we could not conduct a randomized control trial, wherein costeffectiveness analysis would have been a secondary outcome. However, we would like to share that the cost of commercially available bubble CPAP unit is approximately 3 lakh rupees, while the assembled indigenous circuit made from readily available material in any hospital costs only 200 rupees. It would be ideal to have a randomized control trial comparing the safety and efficacy of indigenous bubble CPAP versus commercially available bubble CPAP.

The circuits are used for individual patients and discarded after use. All infection control practices were meticulously adhered to while caring for children admitted to the isolation ward. The circuits are also being used till date routinely in our NICU and PICU without any nosocomial infection outbreaks.

A. Kinikar $(\bowtie) \cdot$ R. Kulkarni $\cdot$ C. Valvi

Department of Pediatrics,

B. J. Medical College \& Sassoon General Hospital,

Pune M. S-411001, India

e-mail: aarti.kinikar63@gmail.com

N. Gupte

Clinical Trials Unit, B. J. Medical College,

Pune M.S, India 